04

\title{
Спектральные характеристики отражения микромассивов кремниевых нанопилларов*
}

\author{
(C) Л.С. Басалаева ${ }^{1}$, Ю.В. Настаушев ${ }^{1}$, Ф.Н. Дульцев ${ }^{1,2}$, Н.В. Крыжановская ${ }^{3}$, Э.И. Моисеев ${ }^{3}$ \\ ${ }^{1}$ Институт фозики полупроводников им. А.В. Ржанова Сибирского отделения РАН, \\ 630090 Новосибирск, Россия \\ ${ }^{2}$ Новосибирский государственный университет, \\ 630090 Новосибирск, Россия \\ ${ }^{3}$ Федеральное государственное бюджетное учреждение высшего образования и науки \\ „Санкт-Петербургский национальный исследовательский Академический университет Российской академии наук“ \\ 194021 Санкт-Петербург, Россия \\ e-mail: basalaeva@isp.nsc.ru
}

Поступила в редакцию 22.12.2017 г.

\begin{abstract}
Проведено исследование спектральных характеристик отражения оптического излучения микромассивами кремниевых нанопилларов в видимом и ближнем ИК диапазоне. Микромассивы кремниевых нанопилларов формируются посредством электронно-лучевой литографии и реактивного ионного травления. Измерены спектры отражения микромассивов с периодом нанопилларов в массиве 400, 600, 800 и $1000 \mathrm{~nm}$. Высота нанопилларов в массиве $0.5 \mu \mathrm{m}$, а диаметр варьировался от 150 до $240 \mathrm{~nm}$. Отмечено, что спектральные особенности отражения обусловлены усилением поглощения отдельными нанопилларами и интерференционными явлениями, возникающими внутри массива. Установлена связь между геометрическими параметрами нанопилларов и особенностями резонансного отражения с учетом влияния подложки.
\end{abstract}

DOI: $10.21883 /$ OS.2018.05.45955.315-17

\section{Введение}

В последние годы резонансное отражение оптического излучения нанопилларами (от англ. nanopillar наностолбик) привлекает значительный интерес исследователей [1-4]. Массивы кремниевых нанопилларов ( $\mathrm{Si}$ НП) могут работать как эффективный сенсор с высокой чувствительностью к изменению показателя преломления среды, которая их окружает [5]. Кроме того, создание оптических фильтров на основе $\mathrm{Si}$ НП (с изменяемыми в широких пределах спектральными характеристиками) представляет интерес для обработки информации, получения цветных изображений и для создания дисплеев [6,7]. Отражательные свойства одиночных нанопилларов с характерной высотой и диаметром порядка длины волны (или $\lambda / 2$ ) часто описывают, опираясь на теорию Ми $[8,9]$. Ми-резонансы можно точно рассчитать для сфер и цилиндров бесконечной длины из аналитического решения уравнений Максвелла. Иной механизм отражения характерен для взаимодействия оптического излучения с одиночным нанопилларом, высота которого превышает длину волны падающего света и составляет от одного до нескольких микрон. При освещении белым светом такой нанопиллар селективно поглощает свет, так как способен поддерживать фундаментальную волноводную моду [10]. При этом относительно мало работ посвящено исследованию микромассивов $\mathrm{Si}$ НП с характерным периодом порядка оптической длины волны. Когда период решетки и длина

\footnotetext{
* Х Международная конференция молодых ученых и специалистов „Оптика 2017“, 16-20 октября 2017 г., Санкт-Петербург, Россия
}

световой волны сопоставимы, можно наблюдать явление дифракции, которое было описано в работах $[11,12]$. Однако исследования коэффициентов отражения Si HП высотой $0.5 \mu \mathrm{m}$ при вариации их диаметра нам неизвестны. Не установлены минимальные геометрические размеры $\mathrm{Si}$ НП, при которых демонстрируется явление сильного резонансного рассеяния света.

В нашей работе экспериментально исследуются отражательные характеристики микромассивов Si HП, пространственно организованных в квадратную решетку с периодом 400, 600, 800, $1000 \mathrm{~nm}$. Мы сформировали структуры Si НП с встроенным вертикальным $p-n$-переходом. Селективное поглощение и фоточувствительность делает такие структуры очень перспективными для различных оптоэлектронных приложений. Высота Si HП в массиве $0.5 \mu \mathrm{m}$, а диаметр варьировался от 150 до $240 \mathrm{~nm}$. Диэлектрические свойства такой среды меняются периодически в двух измерениях с характерным пространственным масштабом периодичности порядка оптической длины волны. Кроме этого, ранее мы одни из первых отработали методику формирования упорядоченных массивов $\mathrm{Si}$ НП посредством электроннолучевой литографии на негативном резисте с последующим реактивным ионным травлением [13-16]. Травление кремниевых наноструктур через маску из алюминия [5] или хрома [8] приводит к дополнительному легированию кремния. В данной работе используется маска из негативного электронного резиста, и присутствие металла исключается на всех этапах формирования нанопилларов. В последнее время такая методика травления нанопилларов через маску из негативного резиста получила 
распространение [17] еще и за счет своей простоты, так как не требуется удалять резистивную маску перед оптическими измерениями. Резистивная маска прозрачна для оптического излучения видимого и ближнего ИК диапазонов [18].

\section{Детали эксперимента}

Si НП были сформированы посредством плазменного травления исходной подложки кремния $\langle 100\rangle$ через маску из негативного электронного резиста. Подложка кремния имела $p-n$-переход, который представлял собой эпитаксиальные структуры, выращенные методом молекулярно-лучевой эпитаксии. На поверхности кремния (100) при температуре $700^{\circ} \mathrm{C}$ выращивался буферный слой кремния толщиной $100 \mathrm{~nm}$, поверх которого при температуре $500^{\circ} \mathrm{C}$ выращивался слой кремния $p$-типа толщиной $100 \mathrm{~nm}$, сильно легированный примесью бора. Затем на подложках кремния с $p-n$-переходом были сформированы массивы Si НП размером $40 \times 40 \mu \mathrm{m}$ посредством электронной литографии и реактивного ионного травления. Для формирования маски в резисте в виде ансамблей пилларов различного диаметра варьировалась электронная доза экспонирования на точку. Подробно процесс формирования Si НП описан в наших работах [13-16]. Следует отметить, что минимальные размеры маски (представляющей собой пиллары в резисте) ограничены влиянием эффектов близости при экспонировании и адгезией пленки к подложке.

Были сформированы микромассивы кремниевых нанопилларов с диаметром от 150 до $240 \mathrm{~nm}$, высотой $0.5 \mu \mathrm{m}$, с периодом 400, 600, 800, $1000 \mathrm{~nm}$. Растровое электронно-микроскопическое (РЭМ) изображение сформированных структур представлено на рисунках $1, a$ и $b$. На рис. $1, b$ видно, что после проведения реактивного ионного травления на стенках нанопилларов остается небольшое полимерное покрытие. Диаметр нанопилларов указывается с учетом оставшегося полимерного покрытия. Спектры отражения измерялись от микромассивов нанопилларов без предварительной отчистки структур от полимерного покрытия.

Спектры отражения от микромассивов Si НП измерялись в диапазоне длин волн от 400 до $1150 \mathrm{~nm}$ в линейно поляризованном свете. Свет падал перпендикулярно подложке. В качестве источника излучения использовалась галогеновая лампа мощностью $100 \mathrm{~W}$, вольфрамовая нить накаливания (источник Spectral Products). Диафрагмированный свет от лампы пропускался через призму Глана-Тэйлора и собирался с помощью объектива Mitutoyo Plan Apo NIR FS x50 NA 0.42 на поверхность образца. Этот же объектив использовался для сбора сигнала, отраженного от образца. Для калибровки сигнала использовалась эталонная золотая пластина. Детектирование сигнала производилось с помощью монохроматора FHR1000 и одноканального охлаждаемого кремниевого
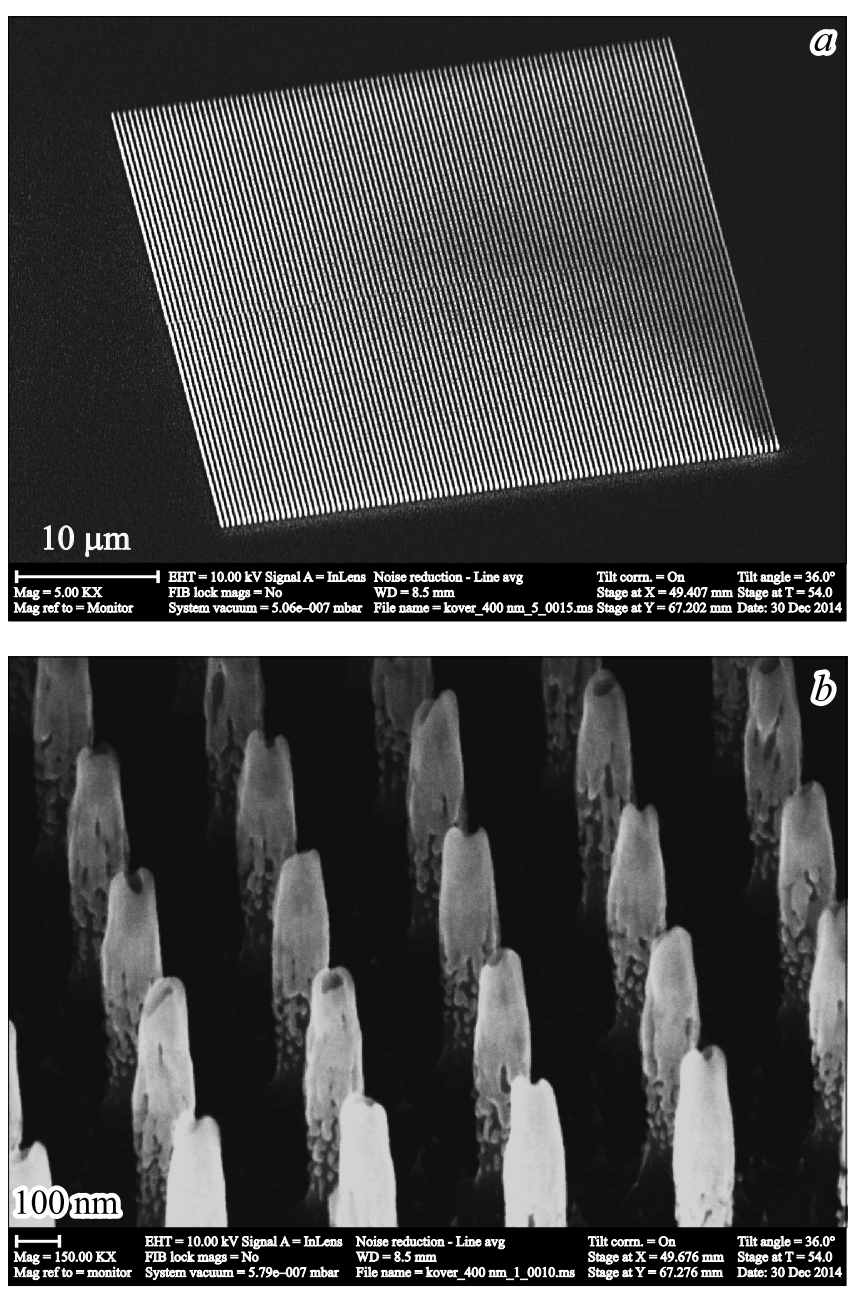

Рис. 1. РЭМ-изображения микромассивов кремниевых нанопилларов, период $400 \mathrm{~nm} ; a-$ микромассив, размер $40 \mu \mathrm{m} \times 40 \mu \mathrm{m}$. Масштабная метка $10 \mu \mathrm{m}$. $b-$ увеличенное изображение нанопилларов. Масштабная метка $100 \mathrm{~nm}$.

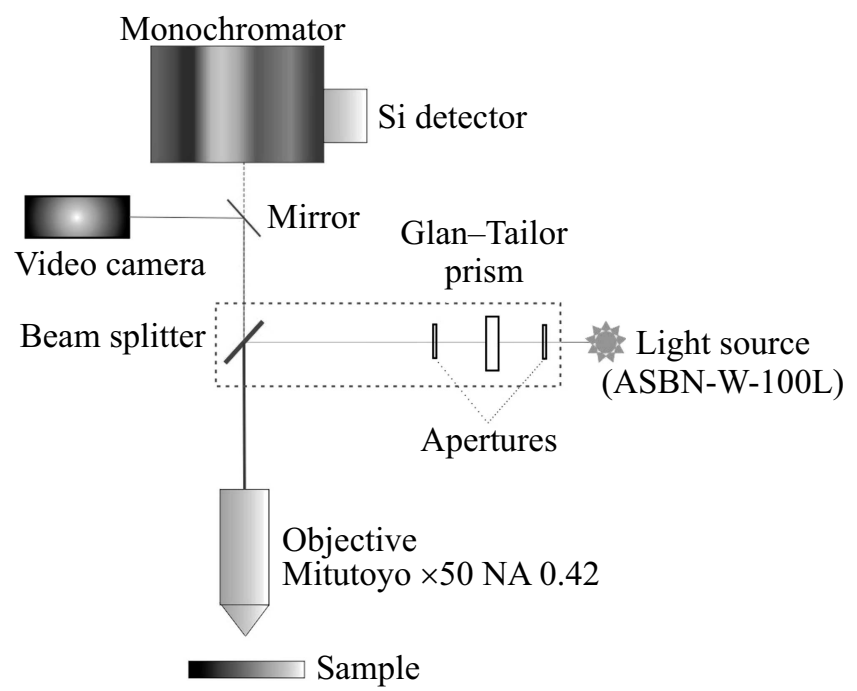

Рис. 2. Схема установки для измерения спектров отражения микромассивов кремниевых нанопилларов. 

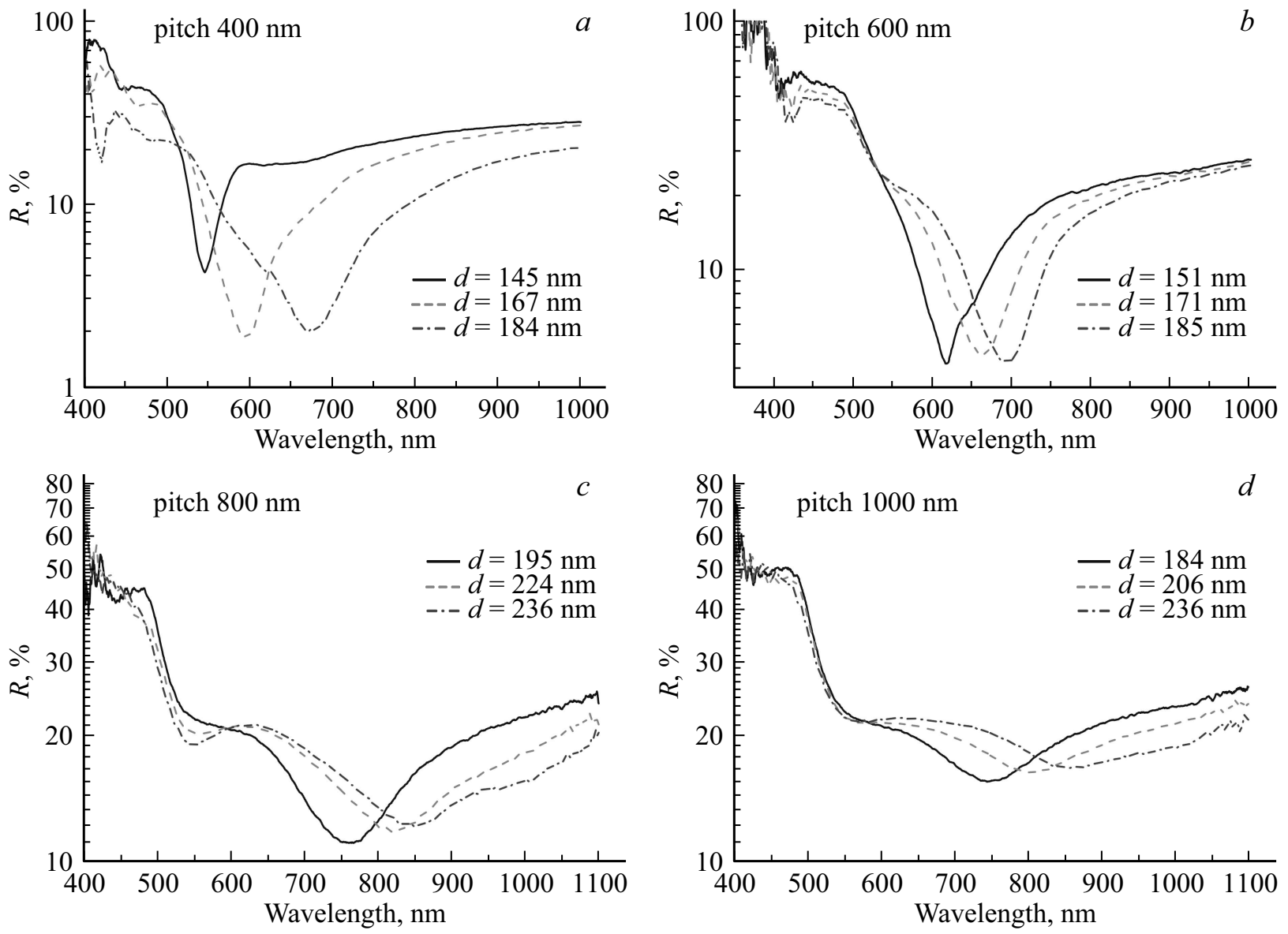

Рис. 3. Спектры отражения кремниевых нанопилларов в массивах с периодом $400(a), 600(b), 800(c), 1000$ nm $(d)$. Диаметры нанопилларов приведены в легенде.

фотодетектора в режиме синхронного детектирования (синхронный детектор Stanford research SR830). Схема установки по измерению отражения микромассивов Si НП представлена на рис. 2.

\section{Результаты и их обсуждение}

Было проведено исследование резонансного отражения света от упорядоченных массивов Si НП в видимом и ближнем ИК спектральных диапазонах. Были сформированы массивы $\mathrm{Si}$ НП высотой $0.5 \mu \mathrm{m}$, диаметром от 150 до $240 \mathrm{~nm}$, период Si НП в квадратной матрице изменялся от $400 \mathrm{~nm}$ до $1 \mu \mathrm{m}$. На оптических изображениях в режиме светлого поля был явно виден структурный цвет микромассивов. Цвет $\mathrm{Si} \mathrm{HП}$ изменяется в зависимости от их диаметра и периода. Были измерены спектры отражения микромассивов Si HП (рис. 3). Резонансные длины волн таких структур находятся в диапазоне длин волн от 400 до $1150 \mathrm{~nm}$.

Для микромассива с диаметром $\mathrm{Si} H$ Н $167 \mathrm{~nm}$ и периодом $400 \mathrm{~nm}$ в минимуме коэффициент отражения достигает $2 \%$ (рис. $3, a$ ). Во всех измеренных спектрах отражения фиксировался один или несколько глубоких минимумов. Причем положение минимума отражения менялось при изменении диаметра $\mathrm{Si}$ НП. Наблюдался сдвиг положения минимума отражения в „красную“ часть спектра при увеличении диаметра $\mathrm{Si}$ НП. Наблюдался сдвиг положения минимумов в „синюю“ часть спектра при уменьшении периода $\mathrm{Si}$ НП в микромассивах с одинаковым диаметром нанопилларов. Второй минимум явно фиксируется в спектре отражения при периоде Si НП 800 и $1000 \mathrm{~nm}$. В случае, когда период больше $1000 \mathrm{~nm}$, т.е. превышает длину волны света, то в минимуме отражение составляет $15 \%$, а при увеличении диаметра $\mathrm{Si}$ НП резонансы еще больше размываются. При увеличении периода (при сохранении общей площади сбора сигнала) число $\mathrm{Si}$ НП в массиве уменьшается, соответственно уменьшается их вклад в отражение. Если период $\mathrm{Si}$ НП становится больше длины волны света (в нашем случае больше $1000 \mathrm{~nm}$ ), то вклад взаимного влияния нанопилларов и интерференционных эффектов становится пренебрежимо малым. Соответственно можно рассматривать такие $\mathrm{Si} \mathrm{HП}$ как одиночные. $\mathrm{He}$ наблюдается зависимости глубины минимумов от длины волны или диаметра Si HП.

На рис. 4 показана экспериментальная зависимость положения минимума отражения от диаметра $\mathrm{Si} \mathrm{HП}$ 


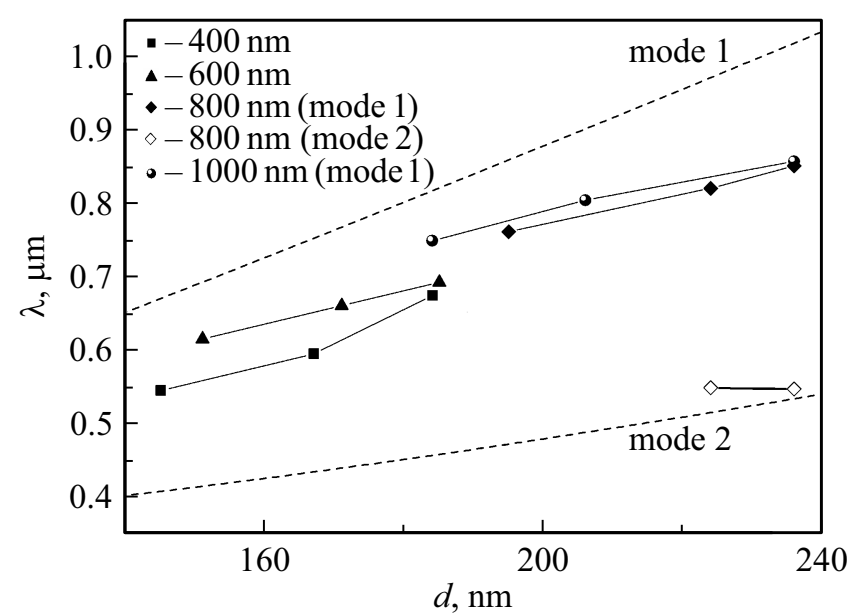

Рис. 4. Зависимость резонансной длины волны от диаметра $\mathrm{Si} \mathrm{HП}$ в легенде указаны периоды нанопилларов в массивах. Штриховые линии показывают результаты расчета для резонансов Ми.

для разных периодов $\mathrm{Si}$ НП в массиве, указан внешний диаметр с учетом полимерного покрытия. Видно, что положение минимума отражения зависит и от диаметра, и от периода нанопилларов в массиве. На рис. 4 штриховой линией приводится теоретическая зависимость, рассчитанная из условия наблюдения резонанса Ми (Mie) для одиночного нанопиллара [8],

$$
n k d=2 K
$$

где $n-$ показатель преломления, $k$ - волновой вектор, $d$ - диаметр $\mathrm{Si}$ НП, $K \sim 2.6$ (для моды 1) и $\sim 5.6$ (для моды 2). Обнаружено, что экспериментальные минимумы отражения, относящиеся к моде 2, располагаются выше по длине волны относительно расчетной зависимости для резонансов Ми, а относящиеся к моде 1 располагаются ниже по длине волны на 50-100 nm.

При этом ранее в научных работах делался акцент на нанопиллары, имеющие геометрические размеры больше длины волны падающего излучения. В нашей работе показано, что свойство сильного резонансного рассеяния света имеют нанопиллары, у которых высота и диаметр меньше длины волны падающего света. Таким образом, снижен порог наблюдаемого эффекта рассеяния. В нашей работе [15] было показано, что нанопиллары с встроенным $p-n$-переходом обладают высокой фоточувствительностью. Таким образом, такие селективно отражающие массивы нанопилларов перспективны для дисплеев, так как исполняя роль фильтра, могут осуществлять фотодетектирование.

\section{Заключение}

В данной работе экспериментально исследовано резонансное отражение света микромассивами Si НП. Si НП высотой $0.5 \mu \mathrm{m}$, имеющие аспектное отношение $2 \div 3$, демонстрируют эффект сильного резонансного рассеяния света. Резонансные длины волн таких структур находятся в диапазоне длин волн: от 400 до $1150 \mathrm{~nm}$. В минимуме коэффициент отражения достигает $2 \%$. В измеренных спектрах отражения фиксировался один или несколько минимумов. При этом положение минимума отражения менялось при изменении диаметра Si НП. Наблюдался сдвиг положения минимума отражения в красную часть спектра при увеличении диаметра Si НП. Наблюдался сдвиг положения минимумов в синюю часть спектра при уменьшении периода $\mathrm{Si}$ НП в микромассивах с одинаковым диаметром нанопилларов. Каждый нанопиллар поддерживает определенные оптические резонансы, однако наблюдается сдвиг резонансной длины волны в зависимости от периода Si НП в массиве. Экспериментально показана возможность управления спектром отражения структур через изменение геометрических параметров $\mathrm{Si}$ НП и периода в квадратной матрице.

Выражаем благодарность за участие в исследованиях и в обсуждении результатов: академику РАН А.В. Латышеву, доктору физ.-мат. наук О.В. Наумовой, к. физ.-мат. наук И.Б. Чистохину. Исследование выполнено при финансовой поддержке РФФИ и Правительства Новосибирской области в рамках научного проекта № 17-42-543293. Эксперименты по измерению оптических характеристик выполнены при финансовой поддержке РФФИ в рамках научного проекта № 16-32-00269 мол_а. Работы по формированию кремниевых нанопилларов частично финансировались за счет гранта Российского научного фонда (проект № 14-22-00143). Использовалось оборудование ЦКП „НАНОСТРУКТУРЫ““. Работа выполнена при поддержке Минобрнауки РФ (проект 3.9787.2017/8.9).

\section{Список литературы}

[1] Yang Z., Jiang R., Zhuo X., Xie Y., Wang J., Lin H. // Phys. Rep. 2017. V. 701. P. 1-50. doi: 10.1016/j.physrep.2017.07.006

[2] Flauraud V., Reyes M., Paniagua-Domínguez R., Kuznetsov A.I., Brugger J. // ACS Photonics. 2017. V. 4. P. 1913. doi: 10.1021/acsphotonics.6b01021

[3] Dhindsa N., Walia J., Saini S.S. // Nanotechnology. 2016. V. 27. P. 495203. doi: $10.1088 / 0957-4484 / 27 / 49 / 495203$

[4] Yue W., Gao S., Lee S.-S., Kim E.-S, Choi D.-Y. // Laser Photonics Rev. 2017. V. 11. N 3. P. 1600285. doi: 10.1002/lpor.201600285

[5] Khorasaninejad M., Abedzadeh N., Walia J., Patchett S., Saini S.S. // Nano Lett. 2012. V. 12. N 8. P. 4228. doi: $10.1021 / \mathrm{nl} 301840 \mathrm{y}$

[6] Park H., Crozier K.B. // Scientific Rep. 2013. V. 3. P. 2460. doi: $10.1038 /$ srep02460

[7] Park H., Dan Y., Seo K., Yu Y.J., Duane P.K., Wober M., Crozier K.B. // Nano Lett. 2014. V. 4. P. 1804. doi: $10.1021 / \mathrm{nl} 404379 \mathrm{w}$

[8] Bezares F.J., Long J.P., Glembocki O.J., Guo J., Rendell R.W., Kasica R., Shirey L., Owrutsky J.C., Caldwell J.D. // Optics Express. 2013. V. 21. N 23. P. 27587. doi: 10.1364/OE.21.027587 
[9] Лойко В.А., Мискевич А.А. // Опт. и спектр. 2017. Т. 122. № 5. C. 825 .

[10] Seo K., Wober M., Steinvurzel P., Schonbrun E., Dan Y., Ellenbogen T., Crozier K.B. // Nano Lett. 2011. V. 11. N 4. P. 1851. doi: 10.1021/n1200201b

[11] Walia J., Dhindsa N., Khorasaninejad M., Saini S.S. // Small. 2013. V. 10. N 1. P. 144. doi: 10.1002/smll.201300601

[12] Самусев К.Б., Рыбин М.В., Лукашенко С.Ю., Лимонов М.Ф. // Опт. и спектр. 2016. Т. 120. N 6. С. 1038; Samusev K.B., Rybin M.V., Lukashenko S.Y., Limonov M.F. // Opt. and Spectrosc. 2016. V. 120. N 6. P. 971.

[13] Golobokova L.S., Nastaushev Yu.V., Dultsev F.N., Gulyaev D.V., Talochkin A.B., Latyshev A.V. // IOP J. Phys.: Conference Series. 2014. V. 541. P. 012074. doi: $10.1088 / 1742$ 6596/541/1/012074

[14] Голобокова Л.С., Настаушев Ю.В., Дульцев Ф.Н., Крыжановская Н.В., Моисеев Э.И., Кохухов А.С., Латышев A.B. // ФТП. 2015. Т. 49. № 7. С. 961; Golobokova L.S., Nastaushev Yu.V., Dultsev F.N., Kryzhanovskaya N.V., Moiseev E.I., Kozhukhov A.S., Latyshev A.V. // Semiconductors. 2015. V. 49. N 7. P. 939.

[15] Golobokova L.S., Nastaushev Yu.V., Talochkin A.B., Gavrilova T.A., Dultsev F.N., Latyshev A.V. // Sol. Stat. Phenomena. 2016. V. 245. P. 8. doi: 10.4028/www.scientific.net/SSP.245.8

[16] Basalaeva L.S., Nastaushev Yu.V., Dultsev F.N. // Materials Today: Proceedings. 2017. V. 4. P. 11341.

[17] Pérez-Chávez V., Simonsen I., Maradudin A.A., Blaize S., Méndez E.R. // Opt. Commun. 2017. V. 399. P. 127. doi: 10.1016/j.optcom.2017.04.027

[18] Yang S.-C., Richter K., Fischer W.-J. // Appl. Phys. Lett. 2015. V. 106. P. 081112 . doi: $10.1063 / 1.4913847$ 